\title{
Transition to university: contributions of a specialist mathematics school
}

Jennie Golding UCL Institute of Education

\begin{abstract}
:
School-university transition in mathematics is of global concern, with multiple cognitive, social and affective disjunctures evidenced. Access to, successful participation in, and retention on, competitive mathematically-intensive degree courses remain particular challenges in England, especially for disadvantaged young people with high mathematical aptitude.

One response has been to establish mathematics specialist schools aimed at such students aged 1618. Early cohorts have achieved encouraging progression to and through such university courses, but more qualitative and longitudinal outcomes have been less well evidenced. The reported study harnessed a student lens and documentary scrutiny to analyse the contribution to building for successful transition of the particular approaches used. Data suggest that the model adopted has initially supported transition to target degree courses well.

I relate the findings to known transition challenges in the global issue of successful passage into and through university mathematics education. I argue many of those are in principle transferable to other post- 16 contexts. The study therefore offers evidence suggesting broadly-applicable specific strategies that can begin to address widely problematic disjunctures in transition.
\end{abstract}

Keywords: Specialist school, mathematical aptitude, enrichment, rigour.

\section{Introduction}

England's education system features all-ability state schools for most young people, including those in the locality studied here, and common national curricula to age 16 . Within state provision, there have been a multiplicity of initiatives targeting young people with particular aptitudes, including in mathematics, where there is perceived to be a significant shortfall of national capacity (ACME, 2011). Provision valued by the mathematics education community has largely centred around enrichment, rather than acceleration (e.g. Gardiner, 2012), though that is sometimes difficult to mould into a coherent mathematical whole. There is in parallel, a persistent inequity of access to high quality pre-16 and pre-university mathematics learning experiences (Cullen et al., 2018), as well as to more competitive mathematics-intense university courses (Montacute, 2018).

In response, and consistent with their free market policies, the 2012 government sought proposals from university-led consortia to establish locally-appropriate specialist mathematics schools for 1618 year olds. Two such schools, 'Daton' ${ }^{1}$ in a large city with high surrounding population density, and 'Ronchester', in a small rural regional city, opened in September 2014; their first cohorts of students graduated from university in Summer 2019. Further such schools have recently been announced (Department for Education, 2017). Key purposes are to enhance equitable access to competitive mathematics-intense university courses, and increase retention on mathematical pathways of young people with significant mathematical aptitude. Here I focus on one such school's contribution to successful transition to and through such university pathways. There is at present little systematic

\footnotetext{
${ }^{1}$ The names of the study school, and of the sample universities, are deducible, but pseudonyms are used to maintain focus on key features rather than the specific institutions.
} 
qualitative evidence around such issues. The reported study contributes to filling that gap, using a survey and a purposive cluster sample of 12 in-depth interviews of students from the first two cohorts through Daton, probing reported experiences and perceptions of their mathematical journeys to date. It identifies specific pre-university approaches to addressing the issue of successful transition, and while the data is sourced from the experiences associated with a specific context, it is argued that most such approaches can be much more widely adopted. A full account of findings in relation to other aspects of the study is given in Golding (2019).

The English mathematics specialist schools initiative took place within global, and especially western, challenges of successful transition to higher mathematics, and a persistently 'leaky pipeline' from compulsory study of mathematics through to mathematically-effective graduation (Clark \& Lovric, 2008). De Guzman et al. (1998) evidenced a range of epistemological, cognitive, social and cultural, as well as didactical, discontinuities between school and university. ICMI 1997 pointed to continuing concern about a 'transition problem', with an overview provided by Gueudet (2008), and di Martino \& Gregorio (2019) pointing especially to affective aspects of that.

In England, a succession of studies have evidenced the challenge: Brown, McCrae, Rodd \& Wiliam (2005) reported a common decreasing enjoyment of mathematics in the years before and through university study, with students from less advantaged backgrounds finding adaptation to university particularly difficult: an issue particularly pertinent to the study in question. With progressively less working structure imposed, the mathematically weakest, and those with least effective study skills, were most vulnerable to that. Pampaka et al. (2012) evidenced the importance of policies aiming at wider university mathematics participation in terms of gender, class and ethnicity. Both studies pointed to the in-university building of a social and working 'mathematics community' as important, especially since a broad range of effectiveness of lecturers was reported. Confident mathematical progression is a very real problem: only $17 \%$ of engineering students surveyed by the Institute of Physics (2011) reported that they were confident using mathematics in their degree, and $21 \%$ claimed that they struggled, despite largely entering university with high mathematics grades. We therefore asked, "What can a specialist mathematics school in England offer to mathematically-rich student progression, and how does that relate to the evidence base around transition to university?"

\section{Transition to mathematics-intensive university courses}

The literature evidences the nature of at least some of the challenges underlying successful transition to and through mathematics-intensive courses at university. Broadly, the findings outlined below apply both to mathematics courses and to mathematics user courses entailing a substantial mathematics content. Both are relevant to the target study population, though school mathematics is the springboard for a variety of mathematical purposes and applications, as well as a variety of courses within each, and disjunctures therefore vary in kind and intensity. The literature suggests there are typically shifts centred on the expected organisation for learning, the forms and purposes of curriculum, pedagogy and assessment, the level of rigour, formalisation and abstractedness of the espoused epistemology, and on a variety of individual level capacities at transition. Although these are widespread globally, they differ in profile across jurisdictions (Hufton \& Elliott, 2000) and between different mathematics-intensive courses and universities within jurisdictions (Gueudet, 2008).

\section{Organisation for learning}

Students typically experience a significant shift in the level and nature of autonomy expected: De Guzman et al. (1998) show that demands on time organisation, note taking, reading mathematical texts, and mathematics specific learning strategies are stretched, there is a shift in the type of 
learning opportunities, and the demands for self-regulated learning increase. Commonly, these are accompanied by an increase in anonymity arising from a large lecture group that magnifies the social distance between teacher and student, as well as between students. The genesis of mathematical knowledge often remains implicit (Gueudet, 2008), so that students have to use more in-depth strategies to access the content and incorporate it into their existing knowledge structures. The combination of such shifts may be appropriate to students' increasing personal, social and academic maturity, but sizeable disjunctures can cause problems (Gueudet, op.cit.)

\section{Forms and purposes of curriculum, pedagogy and assessment}

There is typically an increased tempo and amount of mathematical material to be covered (De Guzman et al., 1998), and teaching approaches adopted on either side of transition might not help: Pampaka et al. (2012) show that a negative experience of transition is associated with common more teacher-centred, transmissionist pedagogies. University lecturers are clearly experts in at least some parts of mathematics but are often less pedagogically knowledgeable than many schoolteachers (De Guzman et al., 1998) though Nardi (2008) showed that at least some such had the potential to develop greater pedagogical awareness. Forms and functions of assessment change (Thomas \& Klymchuk 2012), with assessment often having a lower profile through the year than in schools, so operating differently in terms of motivation. The mathematics valued in assessments can also vary (Darlington, 2014), developing from school assessments to varied extents, but often from what can sometimes be closed, predictable questions demanding reproduction of familiar forms and arguments in some school assessments (ALCAB, 2014), to reflect greater valuing of problem solving, including unstructured, and deeply conceptual abstract reasoning.

In terms of the perceived purposes of mathematics education, school 'utilitarian trends' (Hoyles et al., 2001) can underly another rupture, although the extent of changed purpose varies with the university course followed, and few specific knowledge 'gaps' have been identified. In relation to curriculum, Darlington \& Bowyer (2017) show there can be specific knowledge gaps with which university lecturers are not always familiar, or if they are, think should be addressed at school level (e.g. ALCAB, 2014), but again, those will vary across target university pathway. University researchers might know little about students' prior knowledge and expectations at embarkation of study (Clark \& Lovric, 2009), other than limited information from school assessment outcomes. The character of the mathematical gap varies but typically includes elements of both content and epistemological intent. Further, mathematical tasks at university are also frequently presented as unstructured, in contrast to common school experience (Gueudet, 2008).

\section{Rigour, formalisation and abstraction in epistemology}

Changes in the curriculum breadth are exacerbated by change in the type of mathematical practice and discourse. Hoyles et al. 2001, p832, call this 'a fundamental conceptual divide', and Leviatan (2008, p. 105) 'a cultural divide', with school mathematics often privileging technical aspects (Robert 1998) as opposed to the rigour and abstractness valued by 'scientific' mathematics at university. University mathematics requires engagement with, and criticality in relation to, concept definitions (Jooganah \& Williams 2010, p 116) and Jaworski et al. 2017, p 113 show the different systems sometimes involve contradictory practices - for example, the nature of proof requires an epistemological shift. Tall (1991, p 20) says "The move from elementary to advanced mathematical thinking involves a significant transition: that from describing to defining, from convincing to proving in a logical manner based on definitions" and (2008) describes this as a shift from intuitive to formal mathematical thinking. An Institute of Physics study (2011) quotes an Engineering Professor as saying students had "not quite grasped the essence" of mathematics, and that they seemed to view mathematics as "a language they do not speak, an enemy" (p. 13): in Bernstein's (2000) terms, they need to acquire the recognition rules, in order to recognise the speciality of the discourse. Further, there are in university mathematics multiple semiotic systems associated with analysis, geometry, ... 
and multiple representations of key concepts. Conceptual reasoning, rigour and problem solving are usually more highly valued than at school (ALCAB, 2014). Alcock \& Simpson (2002) show that some school-valued reasoning strategies are inadequate when applied to university mathematics, although they might suffice with the specific objects required by school mathematics, and further, students have to contend with new norms that are often tacit rather than explicit. Tasks in university mathematics are usually more abstract (De Guzman et al., 1998), valuing 'unifying and generalising concepts' (p 752-753): Inglis \& Alcock (2012) identify this as symptomatic of 'expert' versus 'novice' approaches, so a necessary shift inherent to the pathway being followed.

\section{Enculturation/identity}

This transition to more abstract and formal mathematics, with different roles and institutional culture, might be conceptualised as enculturation in advanced mathematical practices (Artique et al. 2007), or as change in identity as students develop with the new social and academic demands of the university (Pampaka et al., 2012). Gueudet (2008) distinguishes between immediate ruptures at transition, and a long enculturation as students become familiar with a new language and new ways of thinking and of mathematical being. But then, student understanding of the nature of mathematics is central to their attitudes to and expectations of undergraduate study and to their sense of 'belonging' and community in university departments (Jaworski et al., 2012). Solomon \& Croft build on Jaworski et al.'s work to suggest that (2016, p.268): "students' relationships with mathematics in terms of their understanding of the nature of mathematics and their self-positioning within mathematics as a developing body of knowledge is what underpins engagement and disengagement: it is not just a matter of ability". They argue that dominant modes of teaching in the English school system produce alienated relationships with mathematics, including among successful students: if students then progress to study a mathematically demanding course, 'undoing alienation' involves the development of new relationships with mathematics through greater support for students' developing confidence in independent mathematical judgement. Probing students' developing relationship with mathematics, and the trajectory of that, was therefore central to our study.

\section{Individual level capacity at transition}

Recent work by Cullen et al. (2018) builds on Montacute's (2018) work to identify that successful progression for disadvantaged high attainers requires a raft of provision, including appropriate academic extension, cultural enrichment, personal development, and removal of financial barriers, so as to equip disadvantaged learners with personal capacity often taken for granted by their more advantaged peers. Equivalent examination results do not necessarily equate to equivalent overall equipment for university thriving.

Once students reach university, Eley \& Meyer (2004) argue that a cognitive-constructivist perspective on learning suggests learners must possess adequate learning prerequisites when challenged by new learning opportunities or academic demands such as those outlined above. Rach \& Heinze (2016) used person-environment fit theories to analyse individual level cognitive and affective characteristics that affected success of transition across a range of students. They identified that perhaps surprisingly, interest and self-concept related to school mathematics did not have an additional impact on study success, though overall school achievement and pre-existing knowledge of 'scientific mathematics' as pursued in the university, did. Overall, individual prerequisites related to school mathematics had only a surprisingly weak connection to those related to scientific mathematics (p. 1356). Students' use of self-explanation as learning strategy, rather than just reproduction of solutions, was another significant predictor for early university success in their study. Success-related characteristics for typical school mathematics and those for scientific 
mathematics therefore differ, and exposure to aspects of 'scientific mathematics' is important to success at university.

Brown \& Rodd (2004) go further, suggesting that successful engagement in undergraduate mathematics is characterised by human flourishing, in the Aristoteleian sense: their 'successful' participants evidenced pleasure in grappling with mathematics, and valued coming to understand it. They also persisted in active engagement with their studies, with focus, perseverance and solutionfocus, even if in very different ways, with different motivations, though accompanied by widely varying conceptions of the discipline. Pathways to achieving such characteristics, though, are not widely evidenced. What we see, then, is that engagement pre-university with a variety of universityvalued mathematical thinking and ways of being, including the value of coming to solutions to challenge through struggle, can set up productive ways of working with university level mathematics, whether within mathematics or as a user of it.

\section{The Study}

The reported study was developed through consultation with the Daton Headteacher and the schools' governing body, as well as a small external advisory group, to answer research questions that included for this paper 'How successfully, and by what means, do Daton students' progression to, retention in, and satisfaction with mathematics-intensive university courses meet key school (and central) aims? To what extent, and by what means, does participation in the school address known transition challenges?' Sub-questions included, 'What have been the pathways and critical experiences for the first cohorts of graduates in relation to Daton and since they left Daton in 2016 or 2017? What have been the perceived impact of concentrated mathematical community, and of teacher expertise? What was their affective development in relation to mathematics, experience of transitions from school to university, retention on the 'mathematical journey'? What related aspects of their mathematics school experiences do alumni perceive to have been distinctive, and how did those impact on successful transition?' The study was initiated and funded by a donor to the school and conducted by the author, an independent researcher. Limitations to that independence are discussed below.

The size and purpose of Daton inevitably brings constraints to curriculum choices, formal and supplementary, and to organisational, including curriculum, enactment, including the involvement of the sponsoring university. Given an annual intake of 60-70 students, the school has offered a curriculum focused on 3 or 4 pre-university 'A Levels', of which two are Mathematics and Further Mathematics. Physics has always been available, together with Economics and/or Computer Studies. There is a wide range of extra-curricular and mathematical enrichment opportunities provided, including work with additional university entrance papers for all thought able to benefit from that, and active promotion of opportunities to visit and otherwise engage with a range of universities. The sponsoring university provides a variety of teaching to complement that of the academically highly-qualified core teaching staff, though not all Daton school teachers have 'qualified teacher status'. Such a concentration of highly specialist teachers, unusual in English schools, inevitably raises ethical issues of 'unfair' concentration in one place, undermining other local provision - versus efficient and appropriate use of a scarce resource. Entrance is via a test and interview, with selection focused on mathematical potential rather than prior attainment.

\section{Methodology}

The first cohort had a somewhat anomalous experience, as initially the only year group in the school, so the study recruited from the first two cohorts to capture reflections on pathways to, through and beyond Daton to Spring 2019. Study participants were thus largely in their second or third year of university education. Main data collection events were as follows: 


\begin{tabular}{|l|l|l|}
\hline When? & What? & Who/what and how? \\
\hline $\begin{array}{l}\text { November } \\
\begin{array}{l}\text { February } \\
2019\end{array}\end{array}$ & $\begin{array}{l}\text { Alumni } \\
\text { googlesurvey }\end{array}$ & $\begin{array}{l}\text { Survey url sent by Headteacher to all alumni who graduated } \\
\text { from Daton in July 2016 or 2017 }\end{array}$ \\
\hline $\begin{array}{l}\text { February- } \\
\text { March 2019 }\end{array}$ & $\begin{array}{l}12 \text { alumni face to } \\
\text { face semi- } \\
\text { structured } \\
\text { interviews, } \\
\text { recorded and } \\
\text { transcribed }\end{array}$ & $\begin{array}{l}\text { Invitation sent by Headteacher to the subset of these } \\
\text { attending Camford or Holder', inviting direct contact with } \\
\text { the researcher, to ensure opt-in of personal data use. } \\
\text { Stratified sub-samples: for each of Camford and Holder, the } \\
\text { first available six giving 3 each male/female, 3 each } \\
\text { 2016/2017 graduation, and 3 each } \\
\text { mathematics/mathematics user degree course3. }\end{array}$ \\
\hline $\begin{array}{l}\text { October } \\
\text { 2018-May }\end{array}$ & $\begin{array}{l}\text { Documentary } \\
\text { analysis }\end{array}$ & $\begin{array}{l}\text { Policy documentation and related 'grey' literature, Daton } \\
\text { website data and the school inspection report analysed, to } \\
\text { inform tool development, analysis and interpretation. }\end{array}$ \\
\hline $\begin{array}{l}\text { June - } \\
\text { August 2019 }\end{array}$ & $\begin{array}{l}\text { Additional alumni } \\
\text { comments }\end{array}$ & $\begin{array}{l}\text { Responses from interviewees to draft (pseudonymised) } \\
\text { report triggered additional, sometimes self-identified 'more } \\
\text { mature', reflections. }\end{array}$ \\
\hline
\end{tabular}

Survey and interview structures were very similar, with interviews offering the opportunity to be more detailed and to probe. Both asked about experiences and key events pre-Daton, through Daton, and post- Daton, in line with the research questions, although this paper is primarily concerned with the latter two phases. The initial intention had been to develop the interview schedule iteratively depending on survey responses, but opt-in to the survey was disappointingly slow and it was important to conduct interviews before the related time commitment would impinge on end of year examination preparation. The survey resulted in 26 sets of responses from students at eight competitive universities (referred to below as S1,..S26), including non-interviewees at Camford and Holder (a 23\% response rate), and 12 interview transcriptions (identified by student pseudonyms).

Thematic analysis proceeded using NVivo, initially using research questions and sub-questions as themes, adding in grounded further themes that emerged from the data, and continuing to theoretical saturation. A full and detailed report of the findings was produced for the school (Golding, 2019), with summary documents being made more widely available. Steps taken to enhance rigour are outlined below; nevertheless, the study outcomes represent intrinsically interpretivist accounts co-constructed by participants and researcher.

\section{Ethical considerations}

The researcher was broadly an 'outsider' to the school although had an historical particular interest and involvement in provision for young people with unusual mathematical aptitude in national education and policy fora. Data collection design, including planned probes, were of course informed

\footnotetext{
${ }^{2}$ Camford is one of the two most competitive 'world-leading' universities in England, and Holder a competitive, wellestablished university. The vast majority of Daton students progress to one of these two 'types' (Daton website), almost always to read mathematics-intensive courses.

${ }^{3}$ e.g. Engineering, Physics, Economics were classified as 'mathematics user' courses, though still mathematics-intensive.
} 
by those experiences, though moderated by school and advisory group input. Given the policy sensitivity of the study, and the commitment to report the range of findings, negative as well as positive, it was particularly important that ethical considerations were shared with the school as well as approved by the researcher's institutional ethics board. Survey participants could opt into sharing names or contact details, for purposes of participant validation and of communication of findings, and all initial contacts were made via the Headteacher. All participants have been identified, here and elsewhere, by pseudonyms, except that survey responses are indicated by e.g. 'S9'. However, in a small school, details of destination university/course of study might be sufficient for informed identification, including of members of staff. Where possible, and as communicated to participants, written reports avoid such detail where not essential to the finding claimed.

Steps taken to validate authenticity of interpretations made, and of effective anonymity, included offering the final report for participant validation, in the case of interviewees and of all survey participants who had offered contact details. In the event, 14 participants responded to this opportunity, including seven to suggest expansion, modification or clarification of responses given and interpretations made, including two who suggested they could still be identified locally from the details used, although in both cases they were content for that to remain so. At every stage, and in communications from both the school and the researcher, it was stressed to participants that the most valuable accounts would be 'no holds barred': the intent was, so far as possible, to access a student lens on their experiences, albeit moderated at that stage by both time and distance.

\section{Student voice:}

The adopted focus on evaluating and identifying opportunities to enhance the effectiveness of transition was aimed at identifying gaps in existing approaches rather than necessarily to seed radical re-thinking of current paradigms of purpose for these students' mathematical education. The intention of using student voice was to better understand the successes and constraints of this model of mathematical preparation for, and passage through, university, broadly within current English systems of school performativity, competitive entrance to university, and marketized career structures, via a student lens, and then to relate those to known transition challenges in other jurisdictions. I argue that if students perceive a pedagogical or social strategy to have been effective in supporting them to and through university, that is a strong argument for its adoption. Other studies primarily adopt student voice to address existing systemic power roles (Taylor \& Robinson, 2009), which was not the core focus here, although some of the emerging approaches of interest will be seen to shift paradigms of knowledge authority through the relationship with mathematics nurtured.

\section{Findings}

In both survey and interviews, Daton alumni were overwhelmingly generous with their time and the depth of reflection offered. Kelley et al. (2003) suggest surveys, particularly of those unknown to the researcher, can result in superficial responses, but that was not the experience here. On the other hand, we do not know how representative the survey sample achieved was. However, completed surveys were, except in individual detail and where noted below, well aligned with one another and with interview responses. Detailed findings, including extensive quotations that exemplify interpretations, are available in Golding (2019). Summary findings here are organised by time (pre-, during, post- Daton), as students gave accounts of their 'mathematical journeys', although the focus of this paper is on the latter two. Findings suggest:

Pre-Daton

A few alumni reported pre-Daton experiences as influential on their choice of university course, but experiences with school curriculum mathematics were often reported unrewarding, consistent with e.g. Montacute, 2018, and Pampaka et al., 2012, though it should be remembered that the sample is likely to be 
skewed by those seeking change at age 16 . A decision to apply to Daton was often linked to critical enrichment experiences, from whatever source - or else had been via an influential teacher or parent. 'Switching on' to mathematics had happened at a variety of stages, and appears often to have stemmed from enrichment, and especially, mathematically challenging additional experience, though 'being unusually good at' more standard school provision was also instrumental for some. Nearly half described their in-depth commitment to mathematics, or a mathematics-using discipline, as stemming only from their time in Daton: "the passion shown by the teachers and the students made lessons so productive and enriching" (S2); " $A$ culture of love for mathematics was for me the most important thing at (Daton), which is plainly available almost nowhere else" (S1).

\section{In-Daton:}

Transition to Daton had been daunting for most, but students had appreciated the induction provision made. Most reported finding the concentrated mathematical community surprisingly 'normal' and affirming, though for two, the concentration remained unhelpfully niche or aspirational, and these alumni were outspoken about perceived limitations to the community in particular, though also to academic provision and expectations: "The huge academic focus and pressure put me off applying for a really academic university like Oxbridge. I wanted to attend somewhere I could have fun outside of my learning" (S22); "I wish we had been able to learn to look after ourselves more... overall people were struggling." (S2). Almost all comments suggested, though, that most had come through any challenges and, at least in retrospect, found the school experience affirming: "The fact that you could make jokes about maths and people would laugh, that was unprecedented" (Michael).

The restricted nature of the main curriculum offer was generally felt to be a necessary limitation, but 'other' subject support was important to students and was felt perhaps to have been less effective than for mathematics. They perceived inevitable challenges of achieving a balanced curriculum that would best support 'user' study, compared with one focused largely on mathematics per se, consistent with e.g. Darlington \& Bowyer (2017).

Most sample alumni reported developing deeper, more rigorous and satisfying relationships with mathematics at Daton, through the provision, inter alia, of multiple deep, rigorous, problem-solving experiences - akin to, but different from, the satisfaction gained from pre-Daton or in-Daton enrichment opportunities: "One day it just sort of clicked and a problem that I had been really struggling with ... opened up a whole new world .....and then I ended up finding it really interesting and taking joy from it" (Otis); "the ability to approach problems from different angles" (S25). They reported extensive experiences of collaborative problem-solving, of developing resilience through engagement with challenging material but of being supported through that, and of coming to know themselves as 'small fish in a big pond' in terms of mathematical aptitude, in contrast to their common experiences pre-16. "I grew to appreciate mathematics as more of a collaborative effort, as a result of being able to have so many discussions about it with my peers" (S1);

It was clear (in uni) a large number of people were now also experiencing the 'I' $m$ suddenly not the best at math' shock (Daton) students know fondly. My own experience with this promoted a rather sympathetic response which probably helped a lot of people bounce back from it with the same drive to improve ...that I developed (S6).

Teacher and visiting expertise was highly valued, while respondents also talked about the pedagogic limitations of some inexperienced teachers, including academics unused to communicating with 16-18 year olds. While they appreciated the intentions behind interactions with university lecturers, a significant minority felt the leap in cognitive and affective functioning expected by university lecturers had for them, in contrast to Borovik's (2017) arguments, been counterproductive: "They weren't the best at teaching stuff. They were too specialised in their own field and that made it quite difficult" (Bill). Alumni suggested that teaching effectiveness was in general not determined by the extent of teachers' academic subject 
knowledge, though they recognised an unusual level of that was needed for a specialist school, but by teachers' pedagogical expertise, and in-depth understanding of relevant school mathematics: "The better teachers are the more experienced ones that are good at breaking down a problem and making it simple to conceptualise, then backing it up with lots of well-informed examples" (S10); "Maths and physics teachers always endeavoured to explain principles thoroughly and followed the 'Socratic teaching' style excellently. This made these subjects much easier and more meaningful" (S18); Students, further, largely reported being well-supported in identifying university pathways, although some still regretted a perceived limited encouragement to apply to the most competitive universities. Those who had studied for, or taken, additional university entrance papers had found the experience mathematically productive and satisfying, but they were also clear that such work, for their own future choices, was subordinate to ensuring optimum performance in A Levels. Even among this elite group of students, then, it would appear that Darlington \& Bowyer's (2018) related recommendations for widespread participation in such papers need to be treated cautiously.

Participants offered a range of relatively small ideas to enhance Daton experience further. These were focused around support for broader experiences and skills to enhance long term whole-person development: "I wish the sport side of the curriculum had been a little better developed throughout my time at (Daton)" (S21), though not usually linked by them to enhanced support for transition to university.

\section{Post-Daton:}

For most participants, this transition was reported to have been a socially and academically relatively smooth process, for some via a refreshing 'gap year': “Critical experiences during university enrolment such joining a community of like-minded, high achieving individuals were not unfamiliar because of (Daton)" (S5); "(I was supported in transition by) the work ethic and true passion for the things we study" (S3). Once at university, small Camford cross-discipline collegiate communities, and small-group tutorials, were particularly appreciated: "you have all these other types of conversation, not only about maths....It's a really exciting community, a cross-discipline college..."(Grace). All participants seemed content with the pathways followed, at least by this point. They frequently pointed to multiple challenges experienced by their university peers, such as having to struggle with the level of work set, working collaboratively to solve problems, organisation for autonomous meaning-making, or meeting the 'small fish, big pond' effect- that Daton graduates had already met, in a smaller and supportive, even if new, environment: "(I benefited from) working in a group to solve problems especially in subjects like maths. Linked to this is the ability to explain the thought processes that have gone into solving a problem. Being able to clearly set out the maths behind thought processes..." (S26). There were, though, some challenges also: "Transition was rough, tutorials/lectures at university were not as fun as learning in the (Daton) classroom. University you can get away with not doing anything, attendance isn't tracked. Had to learn to push myself through" (S17); "I think I struggled initially with how broken up the contact hours were, because I was used to 9-4, five days a week, and then it was all your own time management and blocks of time between which I wasn't used to" (Bill).

University conversations had reportedly increased participants' appreciation of the quality of the mathematical and learning experiences they had experienced at Daton, and the mathematical confidence endowed: "Turned out many people ...lacked the deep understanding that we had in (Daton). This really helped apply this knowledge in a wider context and not just familiar problems" (S19). They had become more aware of a variability of quality of provision received by peers pre-university, but also of some very effective state school teaching elsewhere than Daton. Alumni across both universities and a range of courses claimed the rigorous and problem-solving approaches privileged at Daton had supported them well in transition to university mathematical expectations, as had the work ethic and community inter-dependence, though there was mixed reflection on the to autonomous study skills endowed: "Prepared to be much more independent and in control of my own time was helped a lot by the free periods and (Daton)" (S15); "I felt like I really 
lacked independent learning skills. I was very used to being taught as opposed to seeking out information and learning it myself" (S19).

Although not framed in these terms, it was apparent from much of what was said that Daton had, probably with one exception, supported development of a robust and well-founded mathematical (or mathematicsuser) identity and confidence that had been helpful in adjusting to university, as in Solomon \& Croft (2016): "I definitely feel my mathematical knowledge essentially grew from (Daton). It was planted a seed and it is still growing to this day" (S23). Inevitably, and arguably desirably, individuals' relationships with mathematics had changed further, and often fluctuated, over their time at university, depending in part on their course. For those studying highly mathematics-intensive courses, relationships with university mathematics had often grown to become highly fulfilling: "Really good, I absolutely loved it. I was finally doing the kind of maths I wanted to be doing. It was exactly as I hoped it would be. This year is even better, it's even more exactly what I hoped it would be. (Michael). For users of mathematics their relationship typically evolved over transition into and through university to one of deeply-valued and reliable tool:

In natural sciences... mathematics is no longer something I explore itself, but use it as a skill set to represent, analyse or communicate physical concepts.....The limitations of mathematics as a language that we are still discovering/inventing is more apparent (S5).

One interviewee described it as a "longterm friend, that you could say anything to", and pointed to a more robust relationship than that held by many of their peers from other backgrounds. All participants described a constructive, confident, if often challenging, role for mathematics in their study/work lives: "I feel like I can add value to real world problems now... I feel confident I can add value to employers with my passion for mathematics" (S14). Participants pointed to tensions for Daton in preparing students for a variety of mathematics-rich courses. They largely felt that a robust foundational relationship with mathematics had been built at school, though that had later been 're-envisioned' for differential university purposes.

Key Daton aims:

Participants drew on their own and peers' experiences to argue, remarkably consistently, that Daton had, at least in their experience, fulfilled its mission of enhancing equitable access to mathematically-rich university courses, including to secure establishment in higher education.

In terms of retention on mathematical journeys, alumni felt effective provision had supported an inclination to persist in mathematical engagement, but none reported having felt pressured to continue in pathways other than those to which they were best suited. At the stage of data collection, some clearly felt ready to finish formal education while others were keen to progress into research. Beyond-university career aspirations were varied and often ambitious, but these young people all appeared confident, and wellprepared, for their planned pathway, with many effusive about the foundation for that given by Daton:

While before (Daton) I perceived the mathematical community as something really closed off and far away from me, being exposed to so many amazing, intelligent people at (Daton) completely changed my mind .... and made me feel a confident part of it, and that has supported me to this day (S16).

\section{Discussion}

In summary, then, participants usually reported their two years at Daton personally affirming and mathematically rigorous and satisfying: the type of mathematical enculturation and mathematical identity supported in the school had much in common with that expected at their competitive university, whether in mathematics or mathematics-user courses. These students had met the shifts from 'school mathematics' to new ways of mathematical thinking and being in a highly-structured, highly-supportive environment, rather than on transition from school to university. Daton mathematics teaching was reported 'inspirational', and certainly not 'transmissionist' in Pampaka et al.'s (2012) sense. Transition to mathematically-intense university courses had usually been comparatively smooth and successfully sustained, following that good in-school support. Relationships with mathematics post-school had changed, depending on the nature of university course followed, but for most, developed in appropriately satisfying ways, and continued to develop 
as students progressed through their courses and for some, beyond that. Participants, even those for whom Daton's highly-focused community remained a challenge, perceived strong advantages to themselves and their subsequent pathways, to their time in the school. Counter-narratives, and knowledge of counter-narratives, to this overwhelmingly positive account of impact were very much the exception and limited in scope, although it should be remembered that students with more profound dissatisfaction might not have opted into the study.

How, then, do the apparently successful approaches adopted by Daton relate to other aspects of the literature, that identify a wide range of disruptions at transition to university mathematics? First, it's important to note that much of the literature refers to transition to 'higher mathematics' or 'scientific mathematics' rather than associating that with a particular point in time (Tall, 1991); however, if that transition occurs at the same time as other significant social and organisational changes, mathematical disruption can be exacerbated. Several commonly-disruptive aspects of transition appear to have been addressed while these students were still at school.

In terms of organisation of learning, Daton uses traditional class size for core teaching, not deviating significantly from typical English post-16 norms in terms of time management, or organisation for learning. Alumni identified that they were probably not ready for significantly more working autonomy at age 16 , but that over time transition might have been better supported by an increasing independence of choice about how and where to complete work, and support in learning to read mathematical texts. However, none reported significant challenges in making that adaptation to greater autonomy on transfer to university. They typically reported building up close working relationships with key teachers at Daton, often in the area chosen for further study - but also with peers. They had been expected to work collaboratively, and semi-publicly on whiteboards, in problem solving lessons and non-contact time, and felt such habits built up appreciation of the potential of peer support, transferring well to university.

The forms and purposes of wider curriculum adopted by Daton include website stimulus materials and other outreach initiatives, pre-application. Consistent with Montacute (2018), these functioned to sensitise pre-16s to motivating engagement with mathematics, so that for some, the journey to successful transition into mathematics-intense university study began well before Daton. Once at the school, the teaching approaches adopted for mathematics were essentially connectionist, rather than transmissionist, and frequently described by alumni as 'inspirational', so that enjoyment and satisfaction in the study of mathematics was felt to be contagious. Pedagogy of less experienced or university teachers was sometimes perceived to be less effective, though alumni described still 'catching' mathematics through the enthusiasm of the teacher, even if accessible meaning-making was limited: preparation for greater autonomy at university did not feature in alumni responses at this point. The English education system is performance-intense, with teachers and schools evaluated in terms of examination outcomes; high results are also necessary, if not sufficient, for access to entrance to competitive university courses. Daton alumni reported a clear in-school priority for achievement of top grades in A Level examinations - but also the harnessing of additional university entrance papers and national and international 'mathematics challenges' such as Olympiad papers, for creative and formative use rather than purely to attain prizes or prized university admission. For students coping well with the demands of core A Level work, this latter work functioned to challenge and motivate, as well as to build up a greater mathematical resilience and repertoire of problem-solving approaches. Contrary to the recommendations of Darlington \& Bowyer (2018), though, Daton teachers reportedly argued that a robust grasp of appropriate A Level 'basics' was a necessary prerequisite to fruitful engagement in such activity, and alumni concurred, so even in this elite school, not all students were encouraged to participate.

Daton's mathematics teaching staff would be recognised in any jurisdiction as academically highachieving specialists, and their approach to mathematical rigour, to formalisation and abstraction in epistemology, while usually reported to be appropriate for novices, clearly permeated their approaches to teaching. It is very clear in student accounts that effective teaching for mathematical 
meaning, associated mathematical enrichment classes, and the collaborative problem solving and ambitious mathematical rigour demanded of students served to convey conceptualisations of mathematics more aligned with 'scientific' mathematics than with more usual school approaches, and alumni identified those as supportive of transition: these students had been enculturated in advanced mathematical practices, in Artique et al.'s (2007) terms, while still at Daton. Questions used in class were reported often unfamiliar and unstructured, and the collaborative approaches adopted were widely embraced as building up identity as part of a mathematical community where quality of reasoning and argumentation, and the mathematical journey, were valued as much as the quality of the solution developed, in lie with Jaworski et al. (2012) and Solomon \& Croft (2016).

The Daton curriculum was wider than mathematics, of course, and while alumni were sometimes less effusive about the quality of teaching available beyond mathematics, provision was certainly sufficient for some individual students to both attain highly within those 'user' disciplines of Physics, Economics and Computer Science, and to inspire pursuit of those at university. Additionally, alumni identified significant efforts made by Daton staff to enrich the academic curriculum with cultural, social and sporting opportunities - if sometimes with limited success. Overall, the breadth and depth of curriculum offered certainly included a good degree of academic extension, cultural enrichment, and personal development, as advocated by Cullen et al. for effective provision for disadvantaged able learners. Cullen et al.'s final requirement is for the removal of financial barriers to further study, and alumni reported good access to financial support both during their time at Daton, and in preparation for sourcing financial support through university.

It is clear from the above discussion that Daton alumni felt generously endowed with personal cognitive and affective skills development that had, as Rach \& Heinze (2016) suggest, supported them in transition to university. Nevertheless, there was still some residual disappointment that Daton teachers had not supported more students in even greater aspiration, despite parallel identification of the appropriateness of their eventual pathway. Without exception at the stage of data collection, all of these students felt themselves to be thriving, in Aristoteleian terms. Consistent with Brown \& Rodd (2005), all were significantly focused on, and invested in, their course of choice, and a majority reported successful negotiation of in-course, and future pathway, challenges.

As is clear from ACME (2011) and ALCAB (2014), mathematical provision of this quality is unusual in state schools - or most others - in England, yet there are significant elements here that could be adopted, at least to some degree, in most post-16 institutions, and so contribute to more successful transitions to university. Teachers at Daton possess an unusual depth of knowledge related to more advanced school mathematics, and appear to be able to select from, and re-present that, in ways which are accessible to school students and which build bridges to the ways in which mathematics is known and practised in universities. That expertise is neither widely available nor easily developed. However, the above approaches to study, to building up a mathematically-focused community, to collaborative development of problem solving, to challenge and persistence, to the discursive development of in-depth conceptual grasp, and the overt and deliberate valuing of those, can be deliberately developed in less mathematically-expert departments - and indeed already exist in some schools or colleges.

It is not clear exactly what role the concentrated mathematical community at Daton contributed to effective transition to university, or whether the above benefits could be achieved within a wider curriculum offering: it might well be harder to draw students into a deeply 'scientific' mathematical enculturation.

Concerns around the skewed concentration of knowledge resources are not addressed here, and impact on capacity of surrounding schools and colleges to provide appropriate support was known to be a relatively minor issue in this context, because of the population density in a large city, although that might be significant for other proposed specialist schools. 


\section{Limitations}

The findings reported here focus on transition to mathematics-intense courses at competitive universities, rather than on equity of access issues. They are also highly contextualised: the other established specialist school in England functions in a very different context. There is, though, no suggestion that Daton provides something unique in every aspect. For example, the changes in relationships with mathematics evidenced might not be dissimilar to those acquired in strong mathematical provision elsewhere, and typical academic provision in England includes a significant narrowing of curriculum post-16.

The study does not of course include an input from those Daton alumni who chose not to participate, so the precise degree of typicality of survey respondents - or indeed of interviewees - is unknown, beyond key sampling criteria. There is clearly a bias towards students with time/capacity/inclination to contribute. We, further, reiterate that the accounts reported here are co-constructed by alumni and the researcher, so that despite exhortation to articulate current thinking around experience related to Daton, there is an inevitable selection on the part of all concerned.

As a footnote, much of the concern in England around perceived inequitable access and progression, centres on young people who perform highly at age 11 but who then fail to make progress comparable with that of better-placed peers. Specialist schools that cater only for post-16-year olds, will not at that stage impact the pathways of those who have already 'switched off' from mathematics, or who do not have sufficient self-efficacy to choose to continue, though Daton also works with teachers of younger students.

\section{Conclusion}

The reported study shows that alumni retrospective perspectives suggest Daton, at least in its early years, was fulfilling key aspirations for its students' access to, and progression in, mathematically demanding pathways. The study also identifies particular aspects of Daton provision that accord well with the evidence of what is needed to support successful transition to mathematics-intense university courses. Many of those aspects, though not all, are in principle transferable to most less selective pre-university provision. The findings offer pointers to the pre-university importance of establishing mathematically-active, challenging and collaborative communities of students and teachers that support building of robust mathematical identity, and doing so as part of a mathematical enculturation distinct from, but aligned with, university-valued mathematical cultures - which of course that vary between and within university institutions. Within such a community, students benefit from appropriately re-presented disciplinary epistemology, valuing of robust and rigorous conceptual development, and wide experience, challenge, communication and persistence, particularly with respect to mathematical problem-solving. These need not depend on the existence of a small, mathematically-focused academic community such as that at Daton, but might be easier to achieve in such a context. They also depend critically on teachers' own productive relationships not only with scientific but with school mathematics, and their own deep disciplinary and pedagogical capacity.

All the above aspects of provision are known to contribute to effective transition to mathematicallyintensive university experiences. For the sample students with unusual mathematical aptitude, the concentrated, high-performing community and expertise offered, additionally, appropriately demanding both provision and support, and that appeared to result in a robust mathematical identity aligned with high aspirations. The particular nature and intensity of the teacher expertise available at Daton is not widespread in England, and by definition the nature of the peer group is not common either. In contexts where there is not significant cost to other local provision, including to students of perhaps lesser but still significant mathematical potential, then, there would appear to 
be strong support for the specialist school model adopted. However, I argue that the range of preuniversity providers in mathematics should consider adapting the above approaches in age-, stage-, and context-appropriate ways, and supporting teacher development towards capacity to work with those.

\section{Acknowledgements}

The focus study was funded by a benefactor to Daton, and its development supported by advice from Professor Alison Wolf and Professor Dame Celia Hoyles, to whom I am indebted.

\section{References:}

ACME (2011) Mathematical needs in the workplace and in Higher Education. The Advisory Committee for Mathematics Education, London: The Royal Society. http://www.acmeuk.org/media/7624/acme_theme_a_final\%20\%282\%29.pdf

ALCAB (2014) Report of the ALCAB panel on Mathematics and Further Mathematics. https://alevelcontent.files.wordpress.com/2014/07/alcab-report-on-mathematics-and-furthermathematics-july-2014.pdf

Alcock, L., \& Simpson, A. (2002) Definitions: Dealing with categories mathematically. For the Learning of Mathematics 22, 2, 28-34.

Artique, M., Batanero, C., \& Kent, P. (2007) Mathematics thinking and learning at post-secondary level. In F.K. Lester (Ed.), Second handbook of research on mathematics teaching and learning: National Council of Teachers of Mathematics (pp. 1011-1049). Charlotte: Information Age Publishing.

Bernstein, B. (2000) Pedagogy, symbolic control and identity: theory, research, critique. London: Taylor \& Francis.

Borovik, A. (2017) What can specialist mathematics schools give to students that mainstream schools cannot? The De Morgan Gazette 9, 4, 17-25

Brown, M. \& Rodd, M. (2004). Successful undergraduate mathematicians: a study of students in two universities. Proceedings of the 28th Conference of the International Group for the Psychology of Mathematics Education 4, 97-104

Brown, M., McCrea, S., Rodd, M., \& Wiliam, D. (2005) Full report of research activities and results: Students' experiences of undergraduate mathematics. King's College London.

Clark, M., \& Lovric, M. (2008) Suggestion for a theoretical model for secondary-tertiary transition in mathematics. Mathematics Education Research Journal 20, 2, 25-37.

Cullen, S.M., Cullen, M-A., Dytham, S., \& Hayden, N. (2018) Research to understand successful approaches to supporting the most academically able disadvantaged pupils. London: Department for Education.

Darlington, E. (2014) Contrasts in mathematical challenges in A-level Mathematics and Further Mathematics, and undergraduate mathematics examinations. Teaching Mathematics and its Applications 33, 213-229.

Darlington, E. (2015) What benefits could extension papers and admissions tests have for university mathematics applicants? Teaching Mathematics and its Applications 34, 5-15.

Darlington, E. \& Bowyer, J. (2018) The role of 'extension papers' in preparation for undergraduate mathematics: students' views of the MAT, AEA and STEP Teaching Mathematics and its Applications 37, 122-140

Darlington, E. \& Bowyer, J. (2017) Engineering undergraduates' views of A-level Mathematics and Further Mathematics as preparation for their degree Teaching Mathematics and its Applications: An International Journal of the IMA 36, 4, December 2017, 200-21

De Guzman, M., Hodgson, B. R., Robert, A., \& Villani, V. (1998) Difficulties in the passage from secondary to tertiary education, Proceedings of the International Congress of Mathematicians, Berlin, Documenta mathematica, extra volume ICM 1998, 747-762. 
Department for Education (2017) Building Our Industrial Strategy. Green Paper, at http://bit.ly/2kh3roa.

Di Martino, P., \& Gregorio, F. (2019) The mathematical crisis in secondary-tertiary transition. Int J of Sci and Math Educ 17, 825-843

Gardiner, A.D. (2012) Acceleration or Enrichment? The De Morgan Journal 2, 2, 97-125

Golding (2019) Progression through a mathematics specialist school: a case study of trajectories of the first two cohorts through King's College London Mathematics School. Institute of Education, University College London, available at ...

Gueudet, G. (2008) Investigating the secondary-tertiary transition. Educational Studies in Mathematics 67, 237-254.

Hoyles, C., Newman, K., \& Noss, R. (2001) Changing patterns of transition from school to university mathematics. International Journal of Mathematical Education in Science and Technology 32, 829-845.

Hufton, N. \& Elliott, J. (2000) Motivation to Learn: The pedagogical nexus in the Russian school: Some implications for transnational research and policy borrowing. Educational Studies 26,115136.

Inglis, M. \& Alcock, L. (2012) Expert and novice approaches to reading mathematical proofs. Journal for Research in Mathematics Education 43, 358-390.

Institute of Physics. (2011) Mind the Gap: Mathematics and the Transition from A-levels to Physics and Engineering Degrees. London: Institute of Physics.

Jablonka, E., Ashjari, H., \& Bergsten, C. (2017) 'Much palaver about greater than zero and such stuff': first year engineering students' recognition of university mathematics International Journal of Research in Undergraduate Mathematics Education 3, 69-107.

Jaworski, B., Robinson, C., Matthews, J., \& Croft, A. C. (2012) An activity theory analysis of teaching goals versus student epistemological positions. International Journal of Technology in Mathematics Education 19, 147-152.

Jooganah, K. \& Williams, J. (2010) The transition to advanced mathematical thinking: sociocultural and cognitive perspectives. In M. Joubert \& P. Andrews (Eds.), Proceedings of the 7th British Congress for Mathematics Education (BCME), 113-120. BSRLM.

Kelley, K., Clark, B., Brown, V. \& Sitzia, J. (2003) Good conduct in the practice and reporting of survey research. International Journal for Quality in Healthcare 15, 261-263.

Leviatan, T. (2008) Bridging a cultural gap. Mathematics Education Research Journal, 20, 105-116.

Montacute, R. (2018). Potential for Success: fulfilling the promise of highly able students in secondary schools. London: The Sutton Trust.

Nardi, E. (2008) Amongst mathematicians: Teaching and learning mathematics at the University level. New York: Springer.

Pampaka, M., Williams, J. S., \& Hutcheson, G. (2012) Measuring students' transition into university and its association with learning outcomes. British Educational Research Journal 38, 1041-1071.

Rach, S., \& Heinze, A. (2016) The transition from school to university in mathematics: Which influence do School-related variables have? International Journal of Science and Mathematics Education 15, 7, 1-21.

Robert, A. (1998) Outils d'analyse des contenus mathématiques à enseigner au lycée et à l'université (Tools for the analysis of the mathematical content taught at high school and university). Recherches en Didactique des Mathématiques 18, 139-190.

Solomon, Y. \& Croft, T. (2016) Understanding undergraduate disengagement from mathematics: Addressing alienation. International Journal of Educational Research 79, 267-276.

Tall, D. (1991) Advanced Mathematical Thinking. Kluwer, Dordrecht.

Tall, D. (2008) The transition to formal thinking in mathematics. Mathematics Education Research Journal 20, 2, 5-24. 
Taylor, C. \& Robinson, C. (2009) Student voice: theorising power and participation. Pedagogy, Culture \& Society 17, 161-175.

Thomas, M. O. J., \& Klymchuk, S. (2012) The school-tertiary interface in mathematics: teaching style and assessment practice. Mathematics Education Research Journal 24, 283-300.

Jennie Golding is an Associate Professor at UCL Institute of Education, London. Her background is as a teacher of mathematics from age 5-18, in school leadership and in teacher development. She has worked in mathematics education policy for many years and her research focuses on the policypractice interface. 